\title{
Mars rover meets rock with complex past
}

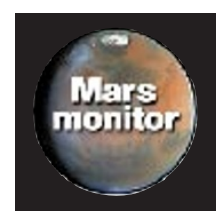

[LONDON] The Mars Pathfinder mission has scored at least one scientific hit to add to its set of technological achievements: the Sojourner rover has analysed the surface of a rock called Barnacle Bill, and found it to be unexpectedly high in silicates.

Sojourner travelled about 3 metres to the rock on 6 July, extending its alpha proton Xray spectrometer (APXS), which uses a radioisotope source to bombard the rock surface with alpha particles, and then takes an energy spectrum of the X-rays, protons and alpha particles that return.

The relative proportions of most of the important elements can be determined in this way. In the case of Barnacle Bill, the measurements imply a silicate content of roughly 58 per cent. This is too high for the most basic category of volcanic rock, basalt, which was expected to be prevalent on Mars's surface.

Barnacle Bill's composition appears to be similar to that of andesite, which on Earth is found above subducted oceanic crust. Either the crust melts, or the mantle melts after the crust has injected water into it; and the melt then erupts from volcanoes to become andesite.

So did Mars once have plate tectonics, similar to those on Earth? If that could be proved, it would be a considerable discovery because, unless one counts the ice plates of Jupiter's moon Europa, there is no planetary body - apart from the Earth — with evidence for plate tectonics.

Unfortunately, there are other ways to make a rock with this composition. Slow cooling in a large magma chamber, for example, could achieve this, especially in the presence of water. (And a great deal of water is believed to be locked in the rocks of Mars,
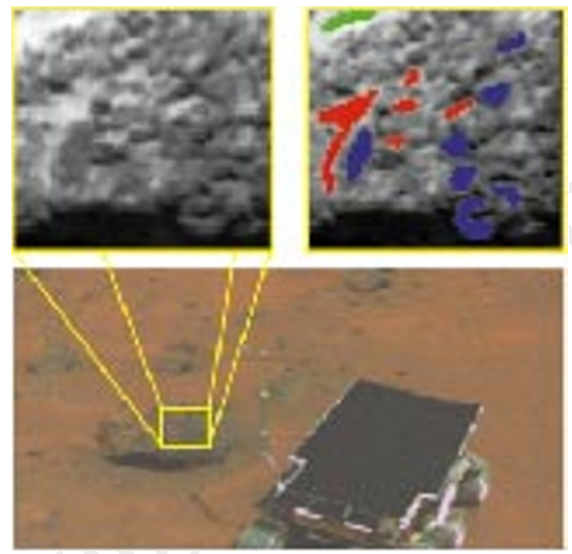

Bill's barnacles: pale soil mottles the face of this otherwise dark volcanic rock, highlighting its rough texture. Singled out for optical spectroscopy, the soil looks like oxidized volcanic rock on Earth. either in the top $10 \mathrm{~km}$ of porous crust, or perhaps in the mantle.) Such a chamber could even have been created by the impact of a large comet or asteroid.

More samples would clearly be welcome. On Wednesday 9 July, the rover drove to another rock, 'Yogi'. But a driver's miscalculation meant that it travelled too far, and was left leaning up against the rock, with the APXS at an unusable angle.

By last Saturday, the controllers at NASA's Jet Propulsion Laboratory in Pasadena had succeeded in ordering it to reverse, but only after a few days of confused communication. The first command was thought to have gone astray last Thursday because of a timing error, so it was resent on Friday. Then on Friday evening the lander's computer reset itself and forgot what it was supposed to tell Sojourner. In fact the original command had gone through.

Sojourner should now have had another go at analysing Yogi before heading for a third target, possibly a rock called Casper, whose paleness may mean an even higher silicon content - or just a fine dust coat.

Meanwhile the lander is collecting weather information and preparing a colour panorama of the area. Up-to-date information can be found at http://mpfwww. jpl.nasa.gov and at many other Web sites around the world.

Stephen Battersby

\section{NASA 'must fill gaps' to finalize streamlined plans for human expedition}

[WASHINGTON] Planners with the US National Aeronautics and Space Administration (NASA) have come up with a 'reference mission' for a human expedition to Mars that would, they suggest, cost about one-tenth the amount of earlier proposed missions.

But the plan is still rough, and there is as yet no political or financial commitment to the project. The agency also lacks some of the technical tools and basic knowledge needed to send people to Mars, according to a report published by the National Academy of Sciences last week.

Even before this month's Pathfinder landing, which has generated more public interest than any other recent space mission, NASA's administrator, Daniel Goldin, had challenged a team of engineers at the Johnson Space Center in Houston, Texas, to find a way of sending humans to Mars in less than a decade for $\$ 25$ billion.
That sum would roughly match the US investment in the International Space Station. A Mars expedition would be expected to launch well after the station is completed, probably between 2010 and 2020.

The Johnson study team has not yet met Goldin's cost target. But it has come within a factor of two, says Lewis Peach, director of advanced projects for NASA's Office of Space Flight. This compares with NASA estimates of the late 1980s, which priced a more complex Mars exploration programme at $\$ 400$ billion.

The current plan would send a crew of six to stay on the surface of Mars for 500 days. Technical innovations that have lowered the cost include inflatable habitats for the crew and the use of in-situ propellant extracting oxygen from the planet's atmosphere to make fuel for the trip home, instead of carrying it on the outward journey to the planet.

Both advances reduce the amount of material launched from Earth. The plan also assumes new economies in future launchers used to reach Earth orbit. The Johnson team briefed Goldin last week on the technological requirements for a human expedition.

NASA is focused on sending robotic spacecraft to Mars at every 26-month launch opportunity between 1998 and 2005. Science has priority on these flights, which will land on the planet in several locations, survey it from orbit, and return rock samples to Earth.

But technology to support future human expeditions will also be developed on the science missions, says Peach. For example, if a prototype fuelproduction plant works as advertised on the 2001 mission, a similar device flown in 2003 could produce enough fuel to launch a small sounding rocket from the

Martian surface carrying scientific experiments.

Not all the hurdles facing a manned expedition relate to hardware. An academy panel warned this week that NASA should be investing more money and attention on the problem of human survival in space if it wants to reach Mars by 2010.

Areas singled out by the panel as needing technological improvement include life support systems, such as waste recycling and food production; environmental monitoring on a Mars ship; space suits for exploring the Martian surface; and human factors such as crew training and scheduling.

Another academy committee said last December that the space agency would also have to improve its understanding of the biological effects of radiation before sending astronauts to Mars.

Tony Reichhardt 